\title{
Raridades em causa: práticas ativistas de pacientes e familiares com doenças raras no Distrito Federal ${ }^{1}$
}

Victor Cezar Sousa Vitor ${ }^{2}$ Universidade de Brasília

Resumo: Neste artigo, apresento trajetórias de vida de presidentas de associações de pacientes com doenças raras residentes no Distrito Federal. Em cada trajetória busquei identificar como se deram as formas de lidar com as especificidades de tais doenças em suas vidas (vivência) ou nas de seus familiares (convivência). Evidencio também como esses casos particulares de reconhecimento e ajuste de uma doença rara ao cotidiano de cuidados e de modos específicos de atenção às especificidades das doenças, de alguma forma, ampliam-se para um projeto moral de cuidado coletivo (causa), permeado pela fundação de uma associação de pacientes.

Palavras-chave: doenças raras; associações de pacientes; esperança; causa coletiva; judicialização dos medicamentos.

\footnotetext{
${ }^{1}$ Este artigo é fruto de pesquisa de campo financiada com recursos do Conselho Nacional de Pesquisa e Desenvolvimento (CNPq), durante período de mestrado no Programa de Pós-graduação em Antropologia Social da Universidade de Brasília (PPGAS/UnB). Agradeço à professora e orientadora Soraya Fleischer e aos colegas do grupo de orientação coletiva pelas contribuições valiosas durante as versões preliminares deste artigo. Agradeço também às pareceristas do referido dossiê pela receptividade ao texto e pelas contribuições adicionais através dos pareceres.

2 Mestre em Antropologia pelo Programa de Pós-graduação em Antropologia Social da Universidade de Brasília (PPGAS/UnB). Possui graduação em Ciências Sociais pela Universidade Federal de Viçosa (DCS/UFV).
} 


\title{
Rarities in cause: practices activists of patients and relatives with rare diseases in the Federal district
}

\begin{abstract}
In this article, I present life trajectories of presidents of associations of patients with rare diseases residing in the Federal District. In each trajectory I sought to identify how the ways of dealing with the specificities of such diseases in their lives (living) or those of their relatives (coexistence) were given. I also evidence how these particular cases of recognition and adjustment of a rare disease to the daily care and specific ways of caring for the specificities of diseases, in some way, extend to a moral project of collective care (cause), permeated by the foundation of a patient association.
\end{abstract}

Keywords: rare diseases; patient associations; hope; collective cause; judicialization of medicines.

\section{Raridades en causa: \\ prácticas activistas de pacientes y familiares con enfermedades raras en el Distrito Federal}

\begin{abstract}
Resumen: En este artículo, presento trayectorias de vida de presidentes de asociaciones de pacientes con enfermedades raras que residen en el distrito federal. En cada trayectoria busqué identificar cómo se daban las formas de tratar las especificidades de tales enfermedades en sus vidas (vivas) o las de sus parientes (convivencia). También declaro cómo estos casos particulares de reconocimiento y ajuste de una enfermedad rara a la atención diaria y formas específicas de cuidar las especificidades de las enfermedades, de alguna manera, se extienden a un proyecto moral de cuidado colectivo (causa), permeado por la fundación de una asociación de pacientes.
\end{abstract}

Palabras clave: enfermedades raras; asociaciones de pacientes; esperanza; causa colectiva; judicialización de medicamentos. 
$\mathrm{T}$ rago neste artigo trajetórias de vida de presidentas de associações de pacientes com doenças raras3 ${ }^{3}$ residentes no Distrito Federal. Há aqui mulheres narrando o surgimento do campo das Raras 4 em suas vidas, assim como essas vivências se constituíram como uma causa coletiva ${ }^{5}$, por meio da fundação ou ingresso em associações de pacientes. Em companhia de seus relatos, busquei compreender como esperanças, praticadas pelas mesmas, tornam vidas possíveis de serem vividas em meio às adversidades da doença rara, conjugada a manutenção rotineira de uma causa coletiva a ser defendida. Trago trajetórias tanto de vivências com a doença, como é o caso de Carmelina e seu diagnóstico de LAM, assim como de convivências, por intermédio de familiares de pacientes, como é o caso de Lauda, Selva e Iolanda, mães de pessoas vivendo com doenças raras.

Em cada trajetória busquei identificar como se deram as formas de lidar com a doença em suas vidas (vivência) ou nas de seus familiares (convivência). Tais narrativas se tornaram significativas para um estudo mais amplo - desenvolvido em minha dissertação de mestrado -, ao considerar que a causa coletiva dessas mulheres são elementos centrais que sustentam a criação e publicização de uma pauta legislativa do Senado Federal, responsável pela proposta de um projeto de lei que institui uma Política Nacional Integral para medicamentos e tratamentos de doenças raras no âmbito do SUS.

Busquei evidenciar como esses casos particulares de reconhecimento e ajuste de uma doença rara ao cotidiano de cuidados e de modos específicos de atenção às especificidades das doenças, de alguma forma, ampliam-se para um projeto moral de cuidado coletivo (causa), permeado pela fundação de uma associação de pacientes. Ou, como a criação das associações de pacientes - e a produção de uma demanda pública -, relacionam-se a suas histórias pessoais, estendendo assim a noção de cuidado ao domínio público, vocalizada como uma demanda por justiça. Isto, tendo em vista a potencialidade com que especificidades em torno da (con)vivência com "a aflição, o sofrimento ou o adoecimento, pode[m] contribuir para que se repense a dinâmica de funcionamento das instituições e dos dispositivos do Estado no campo das políticas públicas, do reconhecimento e dos direitos" (MALUF e ANDRADE, 2017: 177). Um projeto moral permeando biomedicina, cuidado e seus processos de subjetivação e conversão de saberes biossociais (RABINOW, 1999). Para tanto, há engajamentos para tais demandas serem impressas coletivamente como um "problema público" (CEFAÏ, 2009), estabelecendo responsabilidades tanto aos governos quanto a empreendimentos biotecnológicos (grupos de pesquisadores, empresas responsáveis por ensaios clínicos e indústrias farmacêuticas).

Ao considerar esperanças sendo praticadas por pacientes e associações em

\footnotetext{
3 Segundo dados da Organização Mundial da Saúde (OMS), em perspectiva epidemiológica, configuram-se como doenças raras patologias crônicas que afetam até 65 pessoas a cada 100 mil indivíduos $(1,3 / 2.000)$. Dentre cerca de 8.000 doenças raras existentes no mundo, cerca de $80 \%$ são genéticas e $20 \%$ são infecciosas. Em grande parte, trata-se de cronicidades de longa duração, degenerativas, incuráveis e de acesso difícil a diagnósticos e a tratamentos (farmacológicos ou paliativos) gratuitos.

4 Tanto durante entrevistas como em audiências públicas que acompanhei, expressões como campo das raras, os raros, as pessoas raras e os doentes raros tornaram-se frequentes como formas de identificação de grupos de pacientes assistidos pelas associações.

5 Saliento de antemão como procurei textualizar as distinções terminológicas traçadas ao longo do texto. Os termos em itálico são categorias êmicas agenciadas por interlocutores e trechos de discursos citados na íntegra. Os termos entre “aspas" são conceitos teóricos e citações diretas; ou seja, termos aproximados ao tema de pesquisa, mas não necessariamente presentes integralmente nos dados etnográficos desta. Já as categorias de pensamento, também em itálico, são justamente fruto do esforço de imbricação entre categorias êmicas e teoria antropológica trazida pela revisão bibliográfica e em negociação ao longo da textualização do campo.
} 
sessões plenárias do Senado Federal como contexto central da pesquisa de campo do mestrado, foi me despertando a necessidade de investigar as trajetórias individuais impressas na construção da defesa pelo direito à vida reivindicado durante tais eventos legislativos. Assim como na prática de demandar, estabelecer alianças e esperar algo de efetivo a partir da interlocução com instâncias estatais. Para entrar em contato com relatos sobre como essa esperança surgiu na vida de pessoas que representam associações de pacientes - junto ao trabalho diário de refazer esse sentimento em e frente a procedimentos burocráticos -, tornou-se imprescindível identificar: formas de planejamento do cotidiano (presente) e de planos a longo prazo (futuro), construídos em meio as incertezas da continuidade da vida; a criação de alternativas para a aquisição de tratamentos especializados; e as investidas de convencimento bem sucedidas ou frustradas diante de autoridades estatais, como busca por ampliação de redes de apoio.

Inspirado em análise bibliográfica de Adriana Vianna e Laura Lowenkron (2017: 20), junto a uma série de etnografias sobre formas de compreender as relações entre "gênero" e "Estado" como um "duplo fazer", procuro também identificar como as interlocutoras "tematizam, evocam, repudiam e silenciam acerca de instâncias, representações e práticas estatais ou estatizantes” (ibidem). Creio que as narrativas sobre como o campo das Raras surgiu em suas vidas e as formas de comunicação desses dilemas como demanda pública ao Poder Legislativo pode muito nos dizer "sobre o próprio Estado - seja em sua dimensão de ideia ou de sistema - como espaço de disputa ideológica, existencial e política” (ibidem).

Para este artigo, organizei a textualização das experiências expondo, primeiramente, dilemas éticos envolvendo a comunicação de entrevistas e trajetórias de vida; a conjugação entre esperanças e desesperos em um contexto de incertezas característico do contexto das doenças raras; as expertises adquiridas com a didática do cuidado com quem vive com a doença; percepções sobre a noção de raridade; e noções de maternidades e família no referido contexto.

\section{Entrevistas e seus dilemas éticos}

As entrevistas com as quatro representantes de associações de pacientes foram realizadas no Distrito Federal, local onde todas residem. Com exceção da entrevista com Lauda, todas as conversas foram registradas com um aparelho de gravador de voz, sob o pleno consentimento das interlocutoras. A pergunta "tudo bem se eu gravar o áudio da entrevista?" sempre era feita por mim sob certa tensão. O receio de estar sendo invasivo em questões envolvendo a rotina, por vezes desgastante, do cuidado (nestes casos, empreendidos por mães), consigo mesma ou com o ente vivendo com as incertezas de uma doença rara, motivava tal tensão. No entanto, já durante os primeiros momentos das entrevistas, percebi o quanto as interlocutoras desejavam publicizar alguns desses relatos, para fins de reconhecimento público a uma doença rara e desconhecida. Sentido, este, similar ao esforço das mesmas em publicizar a história e o engajamento das associações, diante de gestores públicos em saúde e instâncias estatais, rumo a busca pelo reconhecimento institucional e, assim, a estatização de doenças historicamente invisibilizadas.

A investida pela inclusão do gravador nas conversas era feita logo após o diálogo ter se iniciado de forma descontraída e em meio as apresentações iniciais. Mesmo explicando a cada interlocutora que a entrevista seria totalmente possível caso não fosse autorizada a gravação, reconheci que a minha postura em pedir 
permissão para gravar, após a conversa já ter se iniciado, trouxe consigo um dilema ético. Por um lado, pedir autorização para ligar o gravador pouco depois da conversa ter se iniciado concedia a oportunidade da interlocutora perceber o teor de minhas primeiras perguntas, subsidiando-a de mais elementos para decidir sobre autorizar ou não a gravação.

Por outro lado, o elemento (inconsciente) da descontração e do esquecimento na conversa sem a gravação - ou até o elemento (consciente) do temor em interromper o transcurso do diálogo - poderiam suscitar constrangimentos à entrevistada em interromper a gravação, não a deixando tão à vontade para negar a autorização. Diante disso, devido a minha escolha por uma abordagem menos formal de entrevista - e sim mais próxima a uma dinâmica de conversa (o que não significava me eximir das responsabilidades éticas com as mesmas) -, optei por sustentar possíveis ônus pela escolha dessa forma de abordagem, interpelando-as sobre a possibilidade da gravação após o início do diálogo.

Especificamente nas entrevistas com Carmelina, Selva e Iolanda, ao pedir permissão para gravar os áudios de nossas conversas, notei que todas autorizaram a gravação indicando, no tom de suas respostas, uma intenção em transparecer obviedade ao ato de permitir o registrado em áudio. Interpretei tal conduta como se as interlocutoras quisessem enfatizar não ter empecilho algum para o registro sonoro, como meio de reafirmar, de forma antecipatória, a licitude de suas condutas junto ao campo das doenças raras, diante de um pesquisador desconhecido. Surge aqui mais uma problematização sobre as formas de registros de interlocutores durante a comunicação etnográfica, sob lógica similar a indicada por Mendes de Miranda (2001: 17) acerca da distinção entre "confidência" e "confissão" em pesquisa de campo. Segundo a autora, ao passo que a primeira é realizada via confiança mantida entre pesquisador e interlocutoras, estabelecendo, assim, uma "confidência voluntária", na segunda, o depoimento é anunciado como "prova" ou "confissão imposta" (ibidem).

Com certo mal-estar, a princípio, compreendi a decisão das interlocutoras de enfatizarem a ausência de empecilho em gravar as entrevistas como um depoimento próximo a uma "confissão". Isto, levando em consideração que a autorização do registro de voz tornou-se um meio de autoafirmação de que não haviam nada a esconder, convertendo-se, assim, em um caráter coercitivo da gravação no contexto em que me refiro. Cogitei tal impressão ao passo que suspeitas morais suscitadas por gestores públicos do Ministério da Saúde e por demais instâncias estatais - sobre associações de pacientes potencializarem relações lucrativas de indústrias farmacêuticas no campo da judicialização dos medicamentos órfãos e/ou alto custo - estiveram implicitamente presentes tanto nas justificativas em demasia das interlocutoras, assim como nas sessões plenárias que acompanhei no Senado Federal.

No entanto, creio que o depoimento como "confissão" não foi o aspecto que predominou durante as entrevistas. Devido ao já mencionado anseio das interlocutoras em publicizarem alguns desses relatos para fins de reconhecimento público e socialização de doenças geralmente tratadas como exceções clínicas ${ }^{6}$, a "confidência" se transformava em testemunho como potência estratégica do ativismo, buscando produzir um relato que tivesse o potencial de angariar apoio via

\footnotetext{
${ }^{6}$ Em algumas sessões plenárias e reuniões de gabinete parlamentar que acompanhei durante pesquisa de campo (agosto/2017 a outubro/2018), ouvi relatos de profissionais da medicina genética e de parlamentares com formação biomédica afirmando a existência de um chavão popularizado em cursos de medicina do país que justifica o não aprofundamento (ou ao menos uma abordagem menos rasa) do estudo sobre doenças raras por parte de docentes em tais cursos ao classificarem-nas como casos raros e exceções que raramente são diagnosticadas, justificando assim o não aprofundamento das mesmas ao longo do curso. Aqui, a sua classificação oficial justifica e aprofunda a sua própria condição clínica e social de doença rara.
} 
trajetória narrada. Assim, senti que foi imputada à própria escrita etnográfica um dever ser simultaneamente ético e moral de publicização dos dilemas e demandas a serem registrados. Ético, tendo em vista o dever de não criar, à revelia, expectativas superestimadas das interlocutoras em relação aos desdobramentos da pesquisa. Moral, em relação ao dever de aprofundamento do tema que me senti envolvido e convidado a compartilhar dali em diante junto à causa das Raras. À luz de tal reflexão, decidimos manter todos os nomes verdadeiros das presidentas de associações entrevistadas.

Reconheço que, devido a diversidade de dilemas e desafios suscitados pela dinamicidade das relações etnográficas, como salienta Fonseca (2010: 223), não há "postura única frente à questão do anonimato nos nossos textos". Há uma diversidade de justificativas contextuais em pesquisas de campo voltadas à ocultação de interlocutores, onde a divulgação do verdadeiro nome, a princípio, aparenta não trazer consequências relevantes nem para o trabalho e nem para quem nos propomos falar (BEVILAQUA, 2003: 57). Diante do tema, Fonseca aprofunda a discussão sobre os significados em torno do dilema do anonimato, encontrando justamente na postura de "anonimar" informantes um valor antropológico central. Ela se refere ao "uso de pseudônimos em nossos textos [como] uma maneira de lembrar a nossos leitores e a nós mesmos que não temos a pretensão de restituir a 'realidade bruta"' (FONSECA, 2010: 220) das situações vivenciadas em pesquisa de campo. Segundo a antropóloga, nossa pretensão, "mais coerente com o método etnográfico, é fazer/desfazer a oposição entre eu e o outro, construir/desconstruir a dicotomia exótico-familiar e, para alcançar essa meta, a mediação do antropólogo é fundamental" (ibidem).

No entanto, creio que tanto a decisão por adotar os nomes verdadeiros das interlocutoras, como significativo para a causa, quanto o valor antropológico central de mediação salientado por Fonseca convivem juntos na estratégia de escrita escolhida para este trabalho. Isso porque, compreendi em campo que a produção de conhecimento acadêmico sob o registro dos nomes verdadeiros também pode significar algo muito além de possíveis interesses do escritor acerca de um pretenso anseio estilístico por "veracidade". Assim como os diversos agentes e ambientes do campo das doenças raras, esta produção etnográfica, inevitavelmente (com ou sem os nomes verdadeiros), também foi agenciada pelas interlocutoras como mais um dos instrumentos do ativismo para a socialização das raridades e de publicização de seus dilemas. Mesmo que essa esteja inteiramente montada por ficcionalizações textuais e composições de ideias que transcendem as perspectivas e interesses individuais de cada uma das interlocutoras.

Ainda junto a Fonseca, inspirada em reflexões de Sheila Jasanoff (2005), penso que estabelecer consenso entre interesses "de pesquisa" e interesses das presidentas de associações/interlocutoras produziu um conhecimento via uma "ética científica, concebida como fórum de deliberação democrática, implica[da] [n] a promoção de um ambiente [textual] em que, indo além da cordialidade complacente, explicita-se esse envolvimento e contemplam-se seriamente as perspectivas alternativas (FONSECA, 2010b: 65).

Em todas as conversas, abordei temas como: o longo percurso para obter um diagnóstico preciso para doenças raras; a relação íntima entre pesquisa e tratamento; o sentimento de ajuda coletiva como efeito do engajamento em associações de pacientes; a expertise que familiares e pacientes adquirem junto a saberes biomédicos, jurídicos e de suas leituras dos espaços institucionais que percorrem; e a judicialização dos medicamentos e tratamentos concebida como única alternativa viavél, diante do momento de omissão legislativa sobre o caso. Creio 
que todos esses pontos representam, simultaneamente, segundo Kofes (1994: 120), "a singularidade do sujeito - suas interpretações e interesses -, a interação entre o pesquisador e as entrevistadas, e também uma referência objetiva, que transcende o sujeito e informa sobre o social". Ou seja, informa uma unidade de sentido em comum, perpassando as experiências dessas mulheres representantes de associações de pacientes. Sigo, então, a com alguns dos marcadores identificados nos sentidos que essas representantes de associações de pacientes atribuem às suas decisões e formas de classificação do contexto que às conectam.

\section{Esperanças e desesperos em um horizonte de incertezas}

Em sua narrativa sobre a busca por "socializar uma doença" (RABEHARISOA, 2006: 567) considerada rara, notei que Carmelina7 indicou como fundamental conhecer minimamente tal doença para atingir uma sensação de previsibilidade de suas consequências e assim estabelecer uma percepção sobre uma expectativa de vida. A sensação de incerteza e desespero por não saber o que se tem, acentuada pela frequência com que encontrava profissionais da medicina que também não conheciam a doença, ganhou forma em sua descrição sobre uma doença localizada no âmbito do pode ser.

Sobre o sentimento de incerteza (AURELIANO, 2018: 372), assim como a tentativa de controle do mesmo, me recordo da entrevista com Selva8 ${ }^{8}$ O conhecimento experiencial, criado pela rotina de cuidados com a sua filha, se justifica pela percepção de constante alerta diante da dinâmica imprevisível da doença. Somada a essa constância (do cuidado) diante da inconstância (da doença), há uma automatização de uma leitura especializada diante de situações que possivelmente demandem urgência - como a ocorrência de novo sangramento dentre as lesões -, suscitadas por alguns sintomas da doença, como dores de cabeça e epilepsias de desligamento.

Conviver esperando faz parte da rotina de Selva e de sua filha, Taiga. E, diante desse relato, a interlocutora me fez refletir sobre como tal sensação estabeleceu um novo modo de encarar situações de urgência. Essas situações, condicionadas a doença da filha, não são vivenciadas primeiramente como terminais. Apesar da noção de risco de vida ter sido agenciada por Selva justamente para anunciar a emergência do quadro clínico de sua filha, diante da imprecisão presente na classificação de riscos empregada em recepções hospitalares, a conjugação entre esperança e desespero da mãe transforma a percepção de situação terminal em mais uma situação rotineira de urgência. Mesmo que a urgência seja baseada na imprevisibilidade de uma doença desconhecida, alguns de seus sinais vão sendo apreendidos e assim inscritos na rotina da mãe (como cuidadora) e da filha (como cuidada), em meio a didática de lidar com situações de risco $^{9}$ não

\footnotetext{
7 Carmelina Moura, ex-presidenta da Associação dos Portadores de Linfangioleiomiomatose do Brasil (ALAMBRA), é uma mulher de 50 anos de idade, branca, de estatura baixa, sorridente e de tom de voz calmo. De olhar demorado, transparecia muita calma durante toda a nossa conversa. Além da descontração, suas palavras constantemente se misturavam às risadas. Ao longo do papo falamos da doença com que ela foi diagnóstica há cerca de 12 anos, de nome linfangioleiomioatose pulmonar, popularmente conhecida sob a abreviação $L A M$. Conversamos também sobre associações de pacientes e as formas de contato entre essas, o Poder Público e demais instituições envolvidas com o campo das Raras no Brasil.

${ }^{8}$ Selva Chaves, presidenta da associação Aliança Cavernoma Brasil, é uma mulher de quarenta e poucos anos de idade, branca, alta, mineira, professora formada em pedagogia, de trajes elegantes e de olhos sempre atentos a tela de seu smartphone. Mãe de Taiga, que vive uma doença rara denominada Cavernoma Cerebral, ao lhe comunicar sobre meu interesse de pesquisa, logo ela se disponibilizou para conversarmos na semana seguinte ao contato via WhatsApp por meio da indicação de Carmelina.

9 Para tal análise, me inspiro em Veena Das (1995) e sua noção de "evento crítico" em situações de violência sendo incorporadas a rotina de percepção das pessoas acometidas. No caso a que me refiro, enquanto a incerteza e o extraordinário
} 
apreendidos integralmente por profissionais da saúde.

Destaque também para como a esperança, praticada por Selva e pelo grupo de pesquisadores da Cavernoma, em busca pela estabilização da doença - via processos antecipatórios focados no desenvolvimento de medicamentos e tratamentos específicos -, caminha em sentido contrário e atenuante à dimensão unicamente expectante que sujeita pacientes e familiares ao sentimento inevitável da espera. Assim, na pedida em que a esperança, como prática, impulsiona uma corrida antecipatória contra o tempo para descobrir formas de controle da doença, a condição de espera remete a um contexto de incertezas que se soma aos aspectos crônico, progressivo, degenerativo de doenças raras de origem genética.

É possível explorar como a prática da esperança também depende do sentimento de "desespero" (BREKKE e SIRNES, 2011, apud AURELIANO, 2015: 134) a ser gerido no presente como uma condição a qual não se deve medir esforços para a continuidade da vida, via busca por diversas formas de tratamento. Assim, estratégias de recrutamento, geralmente atribuídas a grupos e a corporações que coordenam ensaios clínicos, foram adotadas pela interlocutora como a única alternativa imediata no horizonte de incertezas sobre a doença, ao aderir a experimentação clínica também como forma de tratamento (PETRYNA, 2011; CASTRO, 2018). Ou, como Carlos Novas (2008: 146) salienta, "a produção de horizontes temporais por meio da potencialização da pesquisa biomédica voltada ao desenvolvimento de curas e tratamentos, proporcionando assim o encurtamento da espera pela inovação tão aguardada”.

Semelhante a Associação Francesa de Distrofia Muscular (AFM), analisada por Rabeharisoa e Callon (2004), Novas nos conta que a Associação Pseudoxantoma Elástico (PXE International), analisada por Terry e Boyd (2001), "demonstra como as pessoas leigas podem não somente se envolver na governança de saúde individual e coletiva, mas também tornarem-se colaboradores ativos e críticos na pesquisa científica" (NOVAS, 2008: 146). No caso de Selva, as relações de reciprocidade entre o grupo de pesquisa em Cavernoma e a fundação da Aliança Cavernoma Brasil estabelece o recrutamento de um número de pacientes pela Associação (ACBra) como sustentador da própria existência do grupo de pesquisadores em Cavernoma no Brasil. Além disso, consequentemente, também pode possibilitar a abertura para a realização de ensaios clínicos e tratamentos em outros países.

\section{Expertises}

Ainda junto ao relato de Selva, destaco a base de conhecimento preciso e especializado que a presidenta da ACBra adquiriu em meio a suas buscas por soluções diante da trajetória incerta e desconhecida traçada pela doença de sua filha. A princípio, Selva adquiriu tal conhecimento conjugando elementos como a proximidade estabelecida com profissionais de medicina especializados em Cavernoma; o acompanhamento da diversidade de quadros clínicos apresentados por pacientes que procuram a Associação para adquirir orientações sobre a doença presencialmente ou via e-mail; e, sobretudo, através da rotina de cuidados específicos demandados pelos sintomas de sua filha.

O padrão de complexidade imputado à doença, tendo em vista o nível de desconhecimento clínico atribuído à mesma pelo próprio campo biomédico, condici-

da doença são rotinizados, nem sempre a ideia de "terminal" e de "limite" são sentidas pelas pessoas envolvidas como tal, ao ponto de exaurir o sentimento de esperança de que será mais uma ocasião de urgência dentre outras. 
onou Selva a hiperespecializar-se para, assim, compreender técnicas de diagnóstico necessárias ao monitoramento do quadro clínico de sua filha e de pacientes com Cavernoma Cerebral vinculados a Associação. Saber ler e interpretar ressonâncias magnéticas na identificação de sangramentos recentes - assim como a condição de estabilidade de cada uma das cinquentas lesões localizadas no cérebro da filha -, apontam para a emergência e a necessidade de dominar e incorporar técnicas de monitoramento específicas de profissionais de saúde (como a leitura de imagens anatômicas em radiologia) no âmbito das práticas de cuidados diários estabelecidos entre mãe e filha. Atrelado a isso, aspectos como não medir esforços diante das incertezas biomédicas sobre a doença e o estabelecimento da confiança com a filha e com os especialistas em Cavernoma, depositada na figura da mãe como uma cuidadora especialista, ganharam destaque como elementos de legitimação de seu saber.

Durante entrevista com Iolanda ${ }^{10}$, também foi possível identificar organizações de pacientes equipando seus membros com uma série de conhecimentos práticos baseados em conhecimentos especializados, presentes na rotina do cuidado e ausentes no espaço hospitalar. Mais precisamente, há uma prática de questionamento das formas de atendimento, de prestação de diagnósticos, de cuidados médicos e socioassistenciais (RABEHARISOA, MOREIRA e AKRICH, 2013: 11), podendo levar grupos de pacientes, familiares e associações a identificarem aspectos ainda não investigados no campo da biotecnologia e da acessibilidade.

Tal questão foi evidenciada por Iolanda ao relatar sobre o momento do parto como responsável por ocasionar o primeiro sinal para a descoberta do diagnóstico de EB. Recorrentemente, a primeira lesão identificada na criança é provocada pelo próprio obstetra responsável pelo parto. Nesse sentido, o hospital torna-se o ambiente cujo o diagnóstico é descoberto justamente via exposição de recém-nascidos ao risco, levando associações, mães e familiares de pacientes com EB a fiscalizarem o modo como crianças e adultos vivendo com a doença são tratados durante toda a trajetória de atendimentos hospitalares.

Ainda, uma doença que, apesar da gravidade, não está estampada explicitamente no corpo da pessoa diagnosticada, foi sinalizado por Selva como outro problema enfrentado por ela e a sua filha Taiga, em atendimentos hospitalares. No caso dessa interlocutora, temos um tipo de enfrentamento peculiar envolvendo uma série de doenças consideradas como graves, raras e de longa duração no campo da cronicidade ${ }^{11}$, ao buscarem construir formas específicas de comunicar estados de urgência e/ou emergência (ou situação-limite) em um contexto de desconhecimento biomédico sobre a doença, perfazendo uma trajetória de "sofrimento de longa duração" (AURELIANO, 2018). Isso, em questionamento a percepções que classificam a condição clínica somente através dos estados físicos visíveis que remetem a debilidade permanente, ou até mesmo eventual, do paciente.

Interessante notar que, ao passo que no caso de Selva o padrão de exposição da doença pela gravidade fisicamente visível dos sintomas foi questionado pela

\footnotetext{
${ }^{10}$ Iolanda, presidenta da Associação de Parentes, Amigos e Portadores de Epidermólise Bolhosa de Brasília (Appeb), é uma senhora de cerca de 60 anos de idade, de pele morena (ou parda), aposentada de funções bancárias e bem observadora. Assim como foi com Selva, contatei-a pelo aplicativo WhatsApp, também por indicação de Carmelina. Contei sobre as minhas intenções já em conversa pelo aplicativo, expondo o meu interesse nas atividades da Appeb, a sua relação com o campo das doenças raras e o desenvolvimento de cuidados com a sua filha, Anna Carolina, de 34 anos, que vive com uma doença rara de nome Epidermólise Bolhosa.

${ }^{11}$ Neste artigo, para compreender cronicidades de longa duração, tomo como base uma série de reflexões de Waleska Aureliano (2018: 372). Em suas palavras, tais condições "são enfermidades com grande potencial de alteração na vida dos sujeitos, tanto em função das limitações biológicas que acarretam quanto das incertezas geradas sobre seu prognóstico" tendo em vista que "muitas doenças raras não têm sequer a perspectiva do controle dos sintomas".
} 
mesma, no caso de Iolanda esta mesma visibilidade é agenciada, estrategicamente, como forma de pressionar agentes públicos (gestores) e políticos (parlamentares) para a urgência de demandas. Assim, Iolanda argumentou sobre a importância em tornar pública ${ }^{12}$ a doença por meio da exposição das condições dos pacientes em espaços de deliberação e decisões político-institucionais.

Sobre a legitimação do status como representante de pacientes, Selva relatou situações em que pessoas com Cavernoma demandam por recomendações sobre formas de tratamento e demais orientações de caráter clínico. Segundo a interlocutora, essas situações extrapolam ao seu papel de representante de associação sem formação no campo biomédico. Em situações como essa, Selva se encontra em um impasse, devido a sua desautorização para orientar pacientes na leitura de seus diagnósticos. O dilema se intensifica na medida em que, por diversas vezes, ela se viu diante de orientações equivocadas de profissionais da medicina, no estabelecimento de diagnósticos e de recomendações, sem o devido conhecimento em Cavernoma.

Suponho que esse dilema traga novos elementos a oposição entre o que Moreira e Palladino (2005) denominam como "regime de verdade" e "regime de esperança" nas relações entre pacientes e pesquisadores no campo da biomedicina, ao analisar tais conceitos diante do relato de Selva. Segundo os autores, ao imaginarmos ser, o "regime da esperança”, um estado em que pacientes estão sempre à espera e prontos para testarem soluções novas e promissoras ainda não testadas, no "regime da verdade", imaginamos pacientes realizando análises de mérito e qualificação dessas alternativas biotecnológicas, que se apresentam com a promessa de prevenir a morte de pacientes que as demandam (MOREIRA e PALLADINO, 2005: 74). No caso do dilema do aconselhamento apresentado por Selva, há um conflito entre "regimes da verdade" em disputa, protagonizado entre o seu conhecimento especializado (em consenso ao conhecimento de profissionais especialistas na doença de sua filha), frente ao conhecimento generalista e não-especializado de profissionais da medicina que, ao contrário de Selva, possuem titularidade para tal exercício de aconselhamento terapêutico.

Ainda no caso de Selva, como representante de uma associação de pacientes, é possível perceber a constituição de um dever ético intermediando os regimes de verdade e de esperança em sua conduta frente aos casos clínicos, analisando e ponderando "soluções novas e promissoras" (esperanças) apresentadas por tais profissionais da saúde não-especializados. Selva adota uma postura ética que simultaneamente pondera equívocos biomédicos oferecidos a pacientes, assim como respeita os limites de sua qualificação para tais aconselhamentos. Por certo, essa ponderação é realizada a partir do contínuo conhecimento (verdades) até então acumulado pelo grupo de pesquisadores com quem a associação mantém vinculação.

\section{Práticas de construção da raridade}

Sobre a forma de classificação atribuída às doenças raras, como patologias de

\footnotetext{
${ }^{12}$ Sobre essa estratégia, em "From representation to mediation: The shaping of collective mobilization on muscular dystrophy in France", Rabeharisoa (2006: 566) conta que familiares vinculados a French Muscular Dystrophy Association (AFM), carregavam como principal meta a restauração "da dignidade humana de seus filhos", procurando assim mostrar que os pacientes com distrofia muscular existem e estão em busca de reconhecimento social para suas doenças. Esses objetivos se traduziam em situações práticas, como familiares levarem seus parentes com distrofia muscular às ruas e em reuniões deliberativas em prefeituras, revelando assim a sua existência, "anteriormente confinado à privacidade de suas casas".
} 
baixíssimo percentual de acometimento por habitante ${ }^{13}$, Selva apontou a subnotificação de casos não diagnosticados e a negligência, via desinteresse de pesquisadores, como indícios que oferecem outra perspectiva frente a definição patológica e estatística de raridade. Ao indicar a subnotificação de casos como um aspecto central para considerar a Cavernoma uma doença rara, a interlocutora buscou desmistificar a noção de doença rara baseada na certeza estatística de que tais patologias são intrinsecamente incomuns e excepcionais. Nesse sentido, Selva apontou para como a negligência sob justificativa do desconhecimento e da raridade (como inabitual) condiciona a noção de gravidade atribuída a mesma, em uma relação de causa e efeito, como elementos que acentuam a subnotificação dos casos de Cavernoma.

No entanto, há estratégias de reconhecimento clínico aplicadas ao diagnóstico da doença, segundo Selva. Devido à falta de diagnósticos oficiais e de tratamentos eficazes para Cavernoma no país - destituída de registro no próprio campo biomédico, como no DATASUS e na Classificação Estatística Internacional de Doenças e Problemas Relacionados com a Saúde (CID) -, utiliza-se a identificação geral de doenças vasculares cerebrais para se ter acesso e assim incorporar a doença a determinadas diretrizes terapêuticas já disponíveis oficialmente.

Diante dessas ausências de normativas, a interlocutora destacou também a inexistência de uma história natural da Cavernoma Cerebral. Esse aspecto evidencia como há um esforço, por parte de grupos de pacientes, familiares e associações, em construir uma história para uma doença oficialmente desconhecida, por intermédio de sua socialização, tanto no campo biomédico quanto no campo jurídico-estatal dos direitos e garantias. Junto às interlocutoras, compreendi por história de uma doença o processo de acumulação de fatos científicos que concedem previsibilidade a aspectos como, o seu teor progressivamente degenerativo, os seus possíveis sinais e sintomas e o reconhecimento social de uma trajetória clínica de busca por tratamento como um direito fundamental (à vida).

Práticas, essas, denominadas por Rabinow (1999) como biossocialidades ${ }^{14}$, grupos de pacientes partilhando distintas experiências, recriando estratégias de cuidado em seus ambientes familiares e ampliando-as aos demais grupos associativos. Mais precisamente, grupos criando redes de "especialistas médicos, laboratórios, histórias, tradições e uma forte intervenção dos agentes protetores para ajudá-los a experimentar, partilhar, intervir, e 'entender' seu destino" (RABINOW, 1999: 147 apud GRUDZINSKI e ROHDEN, 2015: 280).

No entanto, destaco que a noção de história de uma doença desconhecida se diferencia da noção valorativa de história natural destinada a doenças prevalentes ${ }^{15}$ e dotadas de sinais, sintomas e tratamentos já amplamente conhecidos e naturalizados em contextos clínicos. Legitimar a experiência do cuidado diário, reconhecido como leigo - mas empiricamente especializado e que busca uma conversão com a produção de conhecimento científico sobre uma doença subnotificada - torna-se significativo na produção de uma história sobre a mesma ${ }^{16}$. Assim, com a ajuda de Selva, notei a tentativa de evidenciar que ofuturo de certezas

\footnotetext{
13 No Brasil, em média a incidência é de até 65 casos em uma população de 100 mil habitantes.

14 Sobre o amplo conceito de Rabinow (1999), compreendo que seus elementos entram em confluência ao presente estudo em um movimento de retroalimentação de saberes recíprocos entre grupos de pacientes e o campo da biomedicina, da genética médica e da farmacologia, ao ponto em que há uma imprecisão etnograficamente produtiva acerca de qual das partes seria predominantemente e unilateralmente impulsionadora das inovações.

15 Provavelmente de origem epidemiológico, creio que doenças prevalentes são aquelas mensuradas pelo seu acometimento quantitativo e classificadas tendo em vista marcadores geracionais, socioeconômicos, de gênero e até da sobreposição ou conjugação de diagnósticos.

16 Creio que tal conversão promovida por Selva, Taiga e pesquisadores vinculados à ACBra, remete a obra "Gênese e Desenvolvimento de um Fato Científico" (2010). Nesta, Fleck defende a construção de "fatos científicos" como uma atividade
} 
- ao ser posto em um horizonte de antecipação de inovações biotecnológicas, possibilitadas pela prática da esperança na produção experimental de tratamentos para Cavernoma - deve ser continuamente convertido em agora (o presente), para que vidas dotadas de quadros clínicos classificados como à frente de seu próprio tempo biotecnológico prossigam.

$\mathrm{Ou}$, trazê-lo (o futuro de certezas como inovação) para o presente de incertezas, por meio de pesquisas científicas possibilitadas por estratégias jurídico-estatais e de implementação de normativas que abram caminhos mais céleres em instâncias burocráticas de avaliação, incorporação e dispensação de biotecnologias tão esperadas. Encarar ambientes de pesquisa e ensaios clínicos como formas de tratamento evidencia essa tentativa (PETRYNA, 2011; CASTRO, 2018). Procura-se assim "moldar o campo da pesquisa biomédica de acordo com os seus ideais compartilhados coletivamente" (NOVAS, 2006: 289-290), profundamente impulsionado pela "esperança de que a ciência desenvolva rapidamente curas ou terapias, uma vez que o tempo está se esgotando para as pessoas afetadas por determinadas condições genéticas" (idem: 293).

\section{Maternidades como um projeto moral}

Os relatos também evidenciaram expressões sobre um imaginário de maternidade ressignificado e agenciado politicamente pelas presidentas das associações entrevistadas. No relato de Lauda ${ }^{17}$, a construção da maternidade em ativismo foi produzida desde a organização de seus dias a partir dos dias de sua filha Laís, virando dependente da situação, até a extensão de seus significados ao papel de uma mãe de milhões de pessoas adotadas com doenças raras, papel esse atribuído justamente pela própria filha, foco de seus cuidados primários.

A legitimação da extensão (ou coletivização) do cuidado simbolizado como materno justamente a partir do reconhecimento de quem o recebeu primeiramente (a filha com doença rara), também esteve presente nos relatos de Selva. A interlocutora contou que, em certa ocasião pública, sua filha, Taiga, foi indagada se já teria perguntado a si mesma "por que" foi acometida com uma doença rara. Selva relatou com orgulho a resposta da filha, que respondeu "não, eu nunca me perguntei. Mas 'por que foi comigo' 'eu sei que muita gente já foi ajudada'. E aí para mim valeu. Por que foi com a minha filha", completou, Selva. Assim, a filha estendeu tal significado da coletivização do cuidado justamente pela doença tê-la acometido, uma filha cuja mãe possui e despende de uma série de recursos e redes de investigação ampliáveis sobre uma doença desconhecida até por profissionais da medicina.

A figura da mãe como especialista também ganhou destaque como legitimação de seu saber prático tanto nos relatos de Lauda quanto nos de Selva. Ser mãe de uma pessoa com doença rara - e ainda, ter perdido a filha em decorrência da doença, como no caso de Lauda -, parece potencializar um papel de cuidado coletivo atribuído e sinalizado como forma de exercer coletivamente uma dedicação

cooperativa, em contraponto à teoria do conhecimento individualista. Como exemplo, o epistemólogo evidencia a produção difusa - como qualquer outra construção de um fato científico, defende ele -, do conceito de sífilis. No referido contexto de produção do conceito, todos os coletivos de pensamento em disputa pela definição não deveriam ser declarados como falsos, na medida em que todos contribuíram para o que se convencionou a reconhecer como sífilis.

${ }^{17}$ Lauda, presidenta executiva da Associação Maria Vitória (AMAVI), é uma mulher de cabelos lisos e loiros na altura dos ombros, branca, aparenta ter seus 50 anos de idade, estatuto média, funcionária pública formada em Secretariado Executivo e já foi candidata a deputada federal pelo Distrito Federal. Agitada e com celular em mãos, como se estivesse sempre de passagem ou pulando de um compromisso a outro, minha primeira interlocutora sempre se mostrou bastante simpática e disposta a falar. Se envolveu no campo das Raras devido ao diagnóstico de sua filha, Laís, que faleceu aos 27 anos de idade por complicações diretamente associadas à doença, Artrite Reumatoide. 
particular de anos de maternidades produtora de expertises e saberes. Assim, virar um pouco de tudo nesses momentos de ajudar essas famílias, ao virar um pouco médica, um pouco psicóloga, um pouco advogada é a ampliação de uma oferta ou coletivização da atenção, ao passo em que tais atribuições possivelmente já eram praticadas quando a dedicação era depositada somente nos cuidados da filha.

Em contrapartida, nos relatos de Iolanda, apesar do papel de mãe ter sido primeiramente empregado como um vetor condicionante de engajamento em suas buscas por uma parceria materna na fundação de uma associação de pacientes, ao contrário de Lauda e Selva, a interlocutora não reflete elementos da maternidade a sua atuação como presidenta de associação. Ao perguntá-la sobre a forma como era recebida em espaços jurídicos de demanda por tratamentos especializados para EB, Iolanda relatou que "na verdade eu nunca fui como mãe. Eu sempre fui já depois de associação. Eu não posso te falar da experiência como mãe nesses espaços”. Apesar de haver um marcador temporal em sua fala diferenciando papeis circunstanciais, creio que Iolanda classifica o trabalho junto a associação como um cuidado ativista que não se confunde com um tipo de cuidado materno, mesmo que em certos momentos de publicização dos dilemas maternais vivenciados por mulheres que convivem com as doenças raras de seus filhos sejam acionados como explicitação das demandas.

Diante de tal diversidade, creio que a regularidade expressada pelo imaginário materno relatado pelas representantes de associações está na transformação do estatuto de uma mãe lidando com as incertezas de doenças oficialmente desconhecidas e dos cuidados particulares de filhos para mães que lutam em uma rede de cooperação em torno da minimização de incertezas que as condicionam em um mesmo contexto de desassistência. Tal imaginário, praticado como um estatuto em situações de demanda por direitos e de reafirmação de um conhecimento específico sobre as raridades, é coletivamente compartilhado entre elas, fortalecendo o estatuto de mãe que sente e que sabe para acessar o campo jurídico-estatal da política.

Inspiro-me neste ponto em leituras de Young (2012), em companhia de outras teóricas da filosofia política feminista (FRIEDMAN, 1987; OKIN, 1989). As autoras questionam a clássica oposição, de origem iluminista, entre "justiça" e "cuidado", como uma analogia a oposição entre "público" e "privado". Segundo Young (2012: 170), a oposição reproduz distinções entre "papéis institucionais públicos e impessoais, aos quais se aplica o ideal da imparcialidade e da razão formal, por um lado, e relações pessoais e privadas, cuja estrutura moral é diferente, por outro". Este ideal classifica "domínio público" como universalidade de demandas, relegando "diferença, particularidade e corpo para trás, nos domínios privados da família e da sociedade civil" (idem: 171). Assim, creio que o cuidado com uma doença rara, desconhecida, debilitante e degenerativa é reivindicada como uma demanda pública e uma pauta legislativa justamente por meio de papéis tradicionalmente relegados a dimensão privada da vida social: mães e familiares. No caso das entrevistadas, a construção moral do que é ser mãe empreende-se como um saber-poder agenciável no âmbito da causa que maneja e subverte as próprias categorias que às reduzem a dimensão do privado.

Já sobre a noção de família, apesar da categoria mãe ter surgido como marcador de produção de conhecimento especializado e adquirido com a experiência íntima do cuidado, foi possível notar que a categoria familiares (de pacientes com doenças raras), enquanto estatuto legitimador para a publicização de testemu- 
nhos, reivindicações públicas e para demandar direitos esteve mais evidente, entre os discursos de confecção da pauta legislativa no ambiente congressista. Como bem aponta Aureliano (2018: 372-373), doenças raras hereditárias "acaba[m] por afetar e envolver toda a família de diversas formas: o cuidado imediato do familiar afetado, a reorganização do espaço físico da casa, a preocupação com a própria saúde e a da prole, se ela já existir, e de demais parentes consanguíneos". Creio que tal fator em torno de entes familiares como sujeitos políticos, apesar dos envolvimentos desiguais entre os diferentes papéis dentro do ambiente familiar, contribuiu para ativistas apostarem nessa categoria como ampliadora de redes de afetação e de engajamento alheio em sessões plenárias, tendo em vista os múltiplos papéis que ela possibilita acionar em cada pessoa proveniente de alguma família.

Este ponto se relaciona aos próprios alicerces da fundação de uma associação de pacientes. Fundar uma associação aparece como uma decisão virtuosa expressada na atitude de sensibilização ao sofrimento alheio, dotado de valoração moral próprios de uma prática de solidariedade (SONTAG, 2003) como uma significação de ser humano. Neste caso, tal valor é praticado na coletivização de empreendimentos antes depositados particularmente nos cuidados da maternidade e/ou familiar.

\section{Breves conclusões: o que levo sobre a causa?}

Encaminhando para as conclusões, destaco brevemente aspectos fundamentais suscitados pelas entrevistadas, para simultaneamente enquadrar e ampliar as descrições e análises etnográficas acerca do ativismo de pacientes. $\mathrm{O}$ primeiro aspecto diz respeito ao contexto atual de suspeitas que recaem sobre as relações entre associações de pacientes e o mercado de fármacos (indústrias farmacêuticas) acerca da judicialização de medicamentos e tratamentos órfãos e/ou de alto custo.

Neste artigo, a esperança também começou a surgir como tema. Praticar a esperança, em algumas das narrativas, remete a busca por incentivar investigações sobre a doença, com vistas a construir previsibilidade clínica e formas de controle sobre as mesmas, haja vista a necessidade em empregar uma corrida contra o tempo diante do seu caráter progressivo e degenerativo. Destaco também a relação entre esperança e desespero nesse ponto. Ao passo que a prática da esperança, incorporada ao empreendimento de "antecipação" (ADAMS, MURPHY e CLARKE, 2009), luta por modificar um contexto fortemente tomado por incertezas e desespero, diante do risco pela escassez de medicamentos, a sensação de desespero de demandantes não se limita a um enquadramento de falta de perspectivas e de imobilismo. O desespero, publicizado, torna-se uma urgência demandada e em convergência à crença de que haverá uma saída possível para tal situação (sentimento de esperança). Assim, ao passo que o desespero "imediatiza" a demanda pela linguagem da urgência, a esperança busca ampliar e, posteriormente, sistematizar o campo de possiblidades alternativas traçado pela convergência, um tanto conflituosa, entre diferentes "regimes de antecipação" (ADAMS, MURPHY e CLARKE, 2009) empreendidos por associações de pacientes, gestores públicos em saúde, parlamentares e indústrias farmacêuticas. Em seu sentido pragmático, a publicização da esperança também pode ser lida como uma estratégia de convencimento, ao contrário da publicização de desesperanças e de falta de perspectivas, como provocadoras de descrédito diante de agentes públicos (gestores) e agentes políticos. Em sentido amplo, torna-se fundamental 
praticar a esperança para que formas de planejamento do cotidiano via estabilização do risco no presente sejam de possível realização.

A partir da interpretação das entrevistas, não há como alcançar um presente de controle sobre a doença sem que haja um trabalho simultâneo entre a prática do cuidado rotineiro - e sua potência inventiva contida na relação entre cuidador (a) e pessoa cuidada - e a ideia de "futuro biomédico" (Novas, 2008: 145) que a esperança busca presentificar. Tornar um futuro possível de ser experienciado no presente vivido comunica a corrida contra o tempo, regida por uma ética da manutenção da vida como justiça, para descobrir formas de estabilizar uma doença rara, progressiva e degenerativa, ao flexibilizar a distinção entre "pesquisa" como futuro e "tratamento" como presente. Comunica-se também a percepção de urgência de pacientes que buscam formas de gerir o descompasso entre a temporalidade da burocracia estatal em processos de avaliação e de incorporação de medicamentos, a temporalidade da criação do fármaco, a temporalidade do mercado farmacêutico e a temporalidade crônica, progressiva e degenerativa da doença no paciente.

Recebido em 31 de julho de 2019.

Aprovado em 24 de novembro de 2019.

\section{Referências}

ADAMS, Vincanne, MURPHY, Michelle and CLARKE, Adele E. Anticipation: technoscience, life, affect, temporality. Subjectivity 28 (1): 246-265, 2009.

AURELIANO, W. A. Health and the Value of Inheritance: The meanings surrounding a rare genetic disease. Vibrant, 12 (1): 109-140, 2015.

AURELIANO, W. A. Trajetórias Terapêuticas Familiares: doenças raras hereditárias como sofrimento de longa duração. Ciência \& Saúde Coletiva, v. 23 (2): 369-380, 2018.

BEVILAQUA, C. Etnografia do Estado: questões metodológicas e éticas. Campos, 3: 51-64, 2003.

CASTRO, Rosana. Precariedades oportunas, terapias insulares: economias políticas da doença e da saúde na experimentação farmacêutica. Tese (Doutorado em Antropologia Social). Programa de Pós-Graduação em Antropologia Social, Universidade de Brasília, 2018.

CEFAÏ, Daniel. Como nos mobilizamos? A contribuição de uma abordagem pragmatista para a sociologia da ação coletiva. Dilemas: Revista de Estudos de Conflito e Controle Social, 4 (2): 11-48, 2009.

DAS, Veena. Critical Events: An Anthropological Perspective on Contemporary India. New Delhi: Oxford University Press, 1995.

FLECK, Ludwik. Gênese e Desenvolvimento de um Fato Científico. Belo Horizonte: Fabrefactum, 2010. 
FONSECA, Claudia. "O anonimato e o texto antropológico: dilemas éticos e políticos da etnografia em casa”. In: SCHUCH, Patrice; VIEIRA, Miriam S.; PETERS, Roberta (orgs.). Experiências, dilemas e desafios do fazer etnográfico contemporâneo. Porto Alegre: Editora da UFRGS, 2010. pp. 205-227.

GRUDZINSKI, R. R.; ROHDEN, F. "Saúde e biossociabilidade: pensando maneiras de associativismo entre um grupo de pacientes com fibrose cística”. In: ROHDEN, F.; MACCALLUM, C. A. (orgs). Corpo e Saúde na mira da Antropologia: ontologias, práticas, traduções. Salvador: EDUFBA/ABA, 2015. pp. 277300 .

KOFES, Suely. Experiências Sociais, Interpretações Individuais: Histórias de Vida, suas Possibilidades e Limites. Cadernos Pagu, 3: 117-141, 1994.

MALUF, Sônia Weidner; ANDRADE, Ana Paula Müller de. Entre políticas públicas e experiências sociais: impactos da pesquisa etnográfica no campo da saúde mental e suas múltiplas devoluções. Saúde e Sociedade, 26 (1): 171-182, 2017.

MENDES DE MIRANDA, A. Segredos e Mentiras. Confidências e confissões: reflexões sobre a representação do antropólogo como inquisidor. Comum, 6 (17): 91-110, 2001.

MOREIRA, T; PALLADINO, P. Between Truth and Hope: On Parkinson's Disease, Neurotransplantation and the Production of the 'Self'. History of the Human Sciences, 18 (3): 55-82, 2005.

NOVAS, Carlos. Patients, Profits and Values: Myozyme as an Exemplar of Biosociality. In: GIBBON, Sahra; NOVAS, Carlos. Biosocialities, Genetics and the Social Sciences: Making Biologies and Identities. Abingdon: Routledge, 2008.

NOVAS, Carlos. The political economy of hope: patients' organization, science and biovalue. BioSocieties, 1: 289-305, 2006.

PETRYNA, A. Experimentalidade: ciência, capital e poder no mundo dos ensaios clínicos. Horizontes Antropológicos, 17 (35): 127-16o, 2011.

RABEHARISOA, V. From representation to mediation: The shaping of collective mobilization on muscular dystrophy in France. Social Science and Medicine 62 (3): 564-576, 2006.

RABEHARISOA, V.; MOREIRA, T.; AKRICH, M. Evidence-based activism: patients' organizations, users' and activist's groups in knowledge society. CSI Working Papers Series, 33, 2013.

RABINOW, P. "Artificialidade e Iluminismo". In: BIEHL, J. G. (org.). Antropologia da razão: ensaios de Paul Rabinow. Rio de Janeiro: Relume Dumará, 1999. pp. 135-158.

SONTAG, S. Diante da Dor dos Outros. São Paulo: Companhia das Letras, 2003. YOUNG, I. M. O ideal da imparcialidade e o público cívico. Revista Brasileira de Ciência Política, 9: 169-203, 2012. 